\title{
INCIDENCE OF TRACHEAL ASPIRATION IN TRACHEOTOMIZED PATIENTS IN USE OF MECHANICAL VENTILATION
}

\author{
Mariana de Almeida SIMÃo'1, Camila Albuquerque Nobre ALACID¹, Katia Alonso RODRIGUES², \\ Christiane ALBUQUERQUE ${ }^{3}$ and Ana Maria FURKIM ${ }^{4}$
}

\begin{abstract}
Context - Many patients in use of mechanical ventilation show clinical complications due to tracheal aspiration. Assessment and early methods are necessary, so that preventive and safety measures apply to this patients. Objective - To study the incidence of tracheal aspiration of saliva in tracheotomized patients treated in intensive care unit using two modes of mechanical ventilation and with different sedation levels. Method - Prospective study with 14 tracheotomized non-neurological patients using mechanical ventilation. The sample was divided into two groups based on ventilation mode: pressure support ventilation and pressure controlled ventilation. Those two groups were subdivided into two others according to sedation level. The speech pathology evaluation was completed via the blue dye test in order to analyze the incidence of tracheal aspiration of saliva. Results - Sedation levels and mechanical ventilation time related to tracheal aspiration were not statistically significant in this study. On the other hand, ventilation mode and tracheal aspiration showed statistical significance, and there was a higher incidence of tracheal aspiration in the pressure controlled ventilation mode. Conclusion - It was possible to observe a significant relationship between tracheal aspiration incidence and pressure controlled ventilation mode, which means the inclusion of those patients in the risk group for oropharyngeal dysphagia and their insertion in prevention protocols. The relationship between tracheal aspiration and sedation level, as well as tracheal aspiration and mechanical ventilation, were not statistically significant in this sample, needing further research.
\end{abstract}

HEADINGS - Tracheostomy. Respiration, artificial. Deglutition disorders. Respiratory aspiration.

\section{INTRODUCTION}

Mechanical ventilation is indispensable to the maintenance of life mainly in intubated or tracheotomized patients with serious acute respiratory insufficiency in intensive care units (ICU). It is a support method, but not a curative therapy. The use of artificial ventilation is associated with specific complications and its handling must be precise $^{(11)}$

There exist some ventilating modes that can be used. Pressure controlled ventilation (PCV) consists of making patients receive a programmed pressure during a specific time. Pressure support ventilation (PSV) is a parameter used for patients who present an adequate respiratory function, and do not have a minimum predetermined respiratory frequency. This mode is a way toward patients breathing without mechanical ventilation ${ }^{(15,16)}$.

Individuals that depend on mechanical ventilation using orotracheal tubes or tracheotomy may present significant damages in the swallowing function ${ }^{(22)}$. This may result in non coordination between swallowing and breathing, besides morphofunctional alterations such as reduction of laryngeal elevation, pharynx and larynx desensitization, and the reduction of subglottic arterial pressure, which may compromise the swallowing function $^{(7,21)}$. The limitations of the swallowing function may put patients is risk of tracheal aspiration, mainly in cases of prolonged orotracheal intubation ${ }^{(8,21)}$. Some authors have also described tracheotomized patients in mechanical ventilation as being at high risk of tracheal aspiration ${ }^{(7,10)}$.

Tracheal aspiration is defined as the presence of saliva, secretions and/or food residues below the level of vocal folds ${ }^{(2,10,18)}$. One of most serious problems in patients with oropharyngeal dysphagia is the aspiration of saliva and/or food residues ${ }^{(2,12)}$, resulting in pulmonary complications, which may explain the high rates of disease and mortality in this group ${ }^{(2,12)}$.

As the incidence of tracheal aspiration in tracheotomized patients is high ${ }^{(14)}$, an effective tool is needed for observation of patients and for easy application $^{(1)}$. CAMERON et al. ${ }^{(3)}$ introduced the Blue Dye test with a substance used for coloring food in order to identify aspiration of saliva in tracheotomized individuals This is a simple, cheap procedure and can be used in the hospital bed for evaluating tracheal aspiration in the affected group ${ }^{(1,}$ $3,9,17)$. Some authors doubt the precision of this procedure ${ }^{(17)}$ and advise care when using it. However, 
others claim that the procedure is sensible for detecting tracheal aspiration, mainly in individuals submitted to mechanical ventilation ${ }^{(1)}$.

Early identification of tracheal aspiration and treatment must begin in ICU in order to minimize the risk of bronchial aspiration and its respiratory complications ${ }^{(5)}$.

This study had as its objective to research the incidence of tracheal aspiration of saliva in tracheotomized individuals interned in ICU making use of two modes of mechanical ventilation and with different levels of sedation.

\section{METHOD}

From a total of 83 patients, 53 patients were excluded due to the presence of neurological alterations, 2 due to allergy to the artificial dye, 9 due to being submitted to head and neck surgery, 2 due to tracheoesophagic fistula previously diagnosed, and 3 due to their refusal to be part of the research. The sample was composed by 14 tracheotomized patients, with insufflated cuff and using mechanical ventilation, all in the ICU of University "Hospital Pedro Ernesto", in Rio de Janeiro, RJ, Brazil, from June 2006 to March 2007.

Regarding all research subjects, the team responsible for the patients was informed on the objectives, risks and benefits of the research. The individuals that agreed to participate had signed the term of free and informed consent, authorizing the scientific use of collected data. The study was approved by the Committee of Ethics and Research of the institution (1398-CEP/HUPE).

The sample was divided in two groups based in ventilation mode used: PSV and PCV. These two groups were subdivided in two sub-groups according to the level of sedation as defined by Ramsay Scale (level of conscience and interaction). In the first group were patients with level I (anxious and agitated, or uneasy, or both), level II (cooperative, oriented and calm) and level III (only responding to commands and in sleep levels). The second group was constituted by patients with level IV (fast response), level V (slow response) and VI (no response) ${ }^{(20)}$. We must point out that grouping subjects according to levels was necessary due to the number of subjects in the sample.

Data were collected from the patients history using VIDIGAL and GONÇALVES protocol ${ }^{(23)}$, and the following information were analyzed: personal data (name, age and sex), disease, Ramsay scale, ventilating mode, intubation time, tracheotomy time and mechanical ventilation total time. Intubation time was considered the period during which the patient had the orotracheal tube attached until the moment of the accomplishment of tracheotomy. Tracheotomy time was considered the time from the moment of the accomplishment of tracheotomy until the accomplishment of speech therapist's evaluation. Mechanical ventilation total time was defined as the addition of the time of intubation and tracheotomy until the speech therapist's evaluation.

The sample was them submitted to speech therapist's evaluation by means the blue dye test. Saliva was stained by putting three drops of blue dye in the mouth, analyzed by means of direct observation for 15 minutes followed by aspiration through suction done by the physiotherapist before the next application. The application of the blue dye and the direct observation was carried through by a speech therapist. This evaluation was carried through at three moments with intervals of 2 hours in a single day, and were carried through by the same professional.

The test was considered positive $(+)$ for tracheal aspiration of saliva in case of observation of blue content in tracheotomy cannula, in the peritracheal region or else the presence of blue dye in the probe for aspiration by suction at any point of the application of the protocol. The test was considered negative (-) for aspiration of saliva in the absence of blue dye in the tracheotomy cannula, the peritracheal region or in the probe for aspiration by suction at any point of the application of the protocol.

Concerning statistical methodology used to evaluate the relationship of incidence of tracheal aspiration with the level of sedation as well as tracheal aspiration according to ventilation mode, the Fisher test with a 5\% significance level was used. The evaluation of the relationship of mechanical ventilation time and tracheal aspiration was done through Mann-Whitney test with a 5\% significance level.

\section{RESULTS}

In this study 14 patients with an average age of 62.4 years were analyzed $(61.6 \pm 15.8), 3$ female $(21.4 \%)$ and 11 male $(78.6 \%)$. As regards disease, five patients presented pulmonary alterations $(35.7 \%)$, five heart alterations $(35.7 \%)$, two pancreatic alterations $(14.2 \%)$, one lupus $(7.1 \%)$ and 1 presented cirrhosis $(7.1 \%)$.

It was observed that the average time of use of mechanical ventilation with orotracheal tube was $12.8 \pm 8.5$ days and with tracheotomy was $11.9 \pm 9.0$ days. The average total time of use of mechanical ventilation (orotracheal intubation time plus tracheotomy time) by the 14 patients was $25.4 \pm 10.9$ days.

All patients were evaluated by Ramsay scale. Table 1 shows the relationship of tracheal aspiration to sedation level. As regards the incidence of tracheal aspiration in these patients, there was not a significant relationship with sedation level.

Table 2 presents the relationship of tracheal aspiration to total time of mechanical ventilation. The group without tracheal aspiration presented an average 22 days of artificial ventilation and the group with tracheal aspiration presented an average 27.25 days of ventilation. A comparison of the averages of mechanical ventilation times produced no statistical significant results.

It was observed that ventilation mode presented a significant relationship to tracheal aspiration, showing that patients in ventilation by PCV aspirated more frequently when compared with patients in PSV. From the 14 evaluated patients, 6 $(43 \%)$ were in PCV and $8(57 \%)$ in PSV. All patients in PCV aspirated, but in only $2(25 \%)$ did in PSV. Thus, $8(57 \%)$ of the 14 analyzed patients had aspirated (Table 3 ). 
TABLE 1. Distribution (\%) of the incidence of tracheal aspiration of saliva detected by the blue dye test and sedation levels of tracheotomized patients in intensive care unit

\begin{tabular}{|c|c|c|c|c|c|c|c|}
\hline & & \multicolumn{4}{|c|}{ Tracheal aspiration } & \multirow{2}{*}{\multicolumn{2}{|c|}{ Total }} \\
\hline & & \multicolumn{2}{|c|}{ No } & \multicolumn{2}{|c|}{ Yes } & & \\
\hline & & $\mathrm{n}$ & $\%$ & $\mathrm{n}$ & $\%$ & $\mathrm{n}$ & $\%$ \\
\hline Ramsay & no sedation, II, III & 4 & 66.6 & 4 & $50 ., 0$ & 8 & 57.1 \\
\hline Scale & IV, V, VI & 2 & 33.4 & 4 & 50.0 & 6 & 42.8 \\
\hline Total & & 6 & 100.0 & 8 & 100.0 & 14 & 100.0 \\
\hline
\end{tabular}

Fisher test $(P=0,627)$

TABLE 2. Distribution (\%) of averages and standard deviation values of the incidence of tracheal aspiration of saliva detected by the blue dye test and total time of mechanical ventilation of tracheotomized patients in ICU

\begin{tabular}{lccc}
\hline \multirow{2}{*}{ Statistics } & \multicolumn{2}{c}{ Tracheal aspiration } & Mann-Whitney test \\
\cline { 2 - 4 } & No & Yes & $\boldsymbol{P}$ \\
\hline Average & 22,00 & 27,25 & \\
Standard deviation & 6,87 & 11,63 & 0,491 \\
Size & 6 & 8 & \\
\hline
\end{tabular}

TABLE 3. Distribution (\%) of the incidence of tracheal aspiration of saliva detected by the blue dye test and the different ventilation modes of tracheotomized patients in intensive care unit

\begin{tabular}{lcccccccc}
\hline & & \multicolumn{3}{c}{ Tracheal aspiration } & \multicolumn{2}{c}{ Total } \\
\cline { 3 - 7 } & & \multicolumn{2}{c}{ No } & \multicolumn{2}{c}{ Yes } & & \\
\cline { 2 - 7 } & & $\mathrm{n}$ & $\%$ & $\mathrm{n}$ & $\%$ & $\mathrm{n}$ & $\%$ \\
\hline \multirow{2}{*}{ Ventilation mode } & PCV & 0 & 0.0 & 6 & 75.0 & 6 & 42.9 \\
& PSV & 6 & 100.0 & 2 & 25.0 & 8 & 57.1 \\
\multirow{2}{*}{ Total } & & 6 & 100.0 & 8 & 100.0 & 14 & 100.0 \\
\hline
\end{tabular}

Fisher test $P=0,0097^{*}$

\section{DISCUSSION}

The group analyzed in this research is characterized as a risk group for tracheal aspiration of saliva for remaining on mechanical ventilation ( 25.4 days) by orotracheal tube and tracheotomy. An extended time in orotracheal intubation and tracheotomy may damage the swallowing function, causing the reduction of laryngeal elevation, the reduction of pharyngeal and laryngeal sensitivity, alterations of glottic adduction and subglottic air pressure ${ }^{(3,4,7,10,14,18,22)}$, factors that may also favor tracheal aspiration.

SOLH et al. ${ }^{(21)}$ suggested that patients submitted to the orotracheal intubation for more than 48 hours may present significant damages to laryngeal function, thus being at a high risk of tracheal aspiration. In the present study it was observed that $8(57 \%)$ of the 14 analyzed patients had aspirated, corroborating their conclusions.

In our study we observed that the blue dye test could show tracheal aspiration of saliva, as BELAFSKY et al. ${ }^{(1)}$ showed in studies that emphasized the sensitivity of the test, mainly in patients using mechanical ventilation.

A significant relationship of ventilation mode to the incidence of saliva aspiration can be observed. Among patients in PCV, all six had aspirated (100\%) but only two of the eight patients $(25 \%)$ in PSV had done so. Maybe this is due to the fact that patients in PSV are capable of coordinating swallowing and breathing. Moreover, these patients are in recovery as regards breathing, and only receive support mode also used as a way out of mechanical ventilation. In PCV, patients still have a total respiratory dependence due to to requiring more care for their pulmonary condition and need ventilation by controlled pressure as given by the device ${ }^{(11,15,16)}$. This can lead to patients presenting uncoordination between oral and pharyngeal phases of swallowing affecting apnea of swallowing, since this way patients breathing is completely controlled by the device ${ }^{(16)}$

Ramsay scale was used for evaluating patients regarding arousability (conscience and interaction) ${ }^{(20)}$. It was observed that sedation levels of the analyzed patients are not a potentiating factor for aspiration of saliva, and results were not statistically significant. As this may be due to the restricted number of analyzed patients, this point requires further research.

No relationship was observed between mechanical ventilation time and the incidence of tracheal aspiration of saliva, and it is important to emphasize the necessity of more research for confirmation of these data. No statistical analysis was possible between tracheal aspiration and patients' disease due to the broad spectrum of diseases presented by subjects.

SHAKER and $\mathrm{LANG}^{(19)}$ had claimed that healthy old people have greater vulnerability to oropharyngeal dysphagia due to changes in the oral cavity and the pharyngolaryngeal region, which alter the oral and pharyngeal phases of swallowing, factors that may favor tracheal aspiration. Therefore, it can be assumed that aged patients that need drawn out mechanical ventilation are much more susceptible to tracheal aspiration. Curiously, amongst the patients analyzed in the present research, one individual under 60 years of age aspirated, whereas four patients more than 60 years of age had not. This data seem atypical, since the carried through correlations, considering conscience level, seriousness of disease and factors such as orotracheal intubation, tracheotomy and mechanical ventilation time, had not justified tracheal aspiration, even in the presence of worse parameters in the older subjects. Perhaps this is due to the small number of observed patients.

Results showed the incidence of tracheal aspiration in the studied population, and this is a factor to be considered by the multidisciplinary care team working in ICU for preventing worse respiratory complications. 


\section{CONCLUSIONS}

As regards the incidence of tracheal aspiration of saliva by tracheotomized patients using mechanical ventilation in ICU, it was observed that:
1. $100 \%$ of patients in PCV mode had tracheal aspiration; $25 \%$ of patients in PSV mode had tracheal aspiration.

2. No significant relationship was found of the incidence of tracheal aspiration of saliva to sedation levels.

3. No significant relationship was found of the incidence of tracheal aspiration to mechanical ventilation time.

Simão MA, Alacid CAN, Rodrigues KA, Albuquerque C, Furkim AM. Incidência de aspiração traqueal em pacientes traqueostomizados em uso de ventilação mecânica. Arq Gastroenterol. 2009;45(4):311-4.

RESUMO - Contexto - Muitos pacientes em uso de ventilação mecânica apresentam complicações clínicas por apresentarem aspiração traqueal. Métodos de avaliação e detecção precoce são necessários para que medidas preventivas e de segurança se estabeleçam nessa população. Objetivo Pesquisar a incidência de aspiração traqueal de saliva em indivíduos traqueostomizados internados em unidades de terapia intensiva fazendo uso de dois modos de ventilação mecânica e com diferentes níveis de sedação. Método - Estudo prospectivo realizado com 14 pacientes não-neurológicos traqueostomizados em uso de ventilação mecânica. A amostra foi dividida em dois grupos baseada nos modos ventilatórios: ventilação por pressão de suporte e ventilação por pressão controlada. Estes dois grupos foram subdivididos em dois subgrupos, de acordo com o nível de sedação. Foi feita a avaliação fonoaudiológica por meio do teste de anilina culinária azul, a fim de analisar a incidência da aspiração traqueal de saliva. Resultados - O nível de sedação e tempo de ventilação mecânica em relação à aspiração traqueal não foram estatisticamente significantes nesse estudo. Já a relação entre modo ventilatório e aspiração traqueal apresentou significância estatística, sendo que houve incidência maior de aspiração traqueal no modo ventilação por pressão controlada. Conclusão - Pôde-se observar relação significativa entre a incidência da aspiração traqueal e o modo ventilatório ventilação por pressão controlada, o que pode implicar na inclusão desses pacientes no grupo de risco para disfagia orofaríngea e sua inserção nos protocolos de prevenção. A relação entre aspiração traqueal e níveis de sedação, bem como aspiração traqueal e tempo de ventilação mecânica não foram estatisticamente significantes nessa amostra, necessitando de futuros estudos.

DESCRITORES - Traqueostomia. Respiração artificial. Transtornos de deglutição. Aspiração respiratória.

\section{REFERENCES}

1. Belafsky PC, Blumenfeld L, LePage A, Nahrstedt K. The accuracy of the modified Evan's blue dye test in predicting aspiration. Laryngoscope. 2003;113: 1969-72.

2. Brady SL, Hildner CD, Hutchins BF. Simultaneous videofluoroscopic swallow study and modified Evan's blue dye procedure: an evaluation of blue dye visualization in cases of known aspiration. Dysphagia. 1999;14:146-9.

3. Cameron JL, Reynolds J, Zuidema GD. Aspiration in patients with tracheostomies Surg Gynecol Obstet. 1973;136:68-70.

4. Conway DH, Mackie C. The effects of tracheostomy cuff deflation during continuous positive airway pressure. Anesthesia. 2004;59:652-7.

5. Costa H, Luz M, Carmona MJ, Cardoso E, Isosaki M, Auler Jr. JO. Reintrodução da alimentação oral em pacientes traqueostomizados com terapia de nutrição enteral. Rev Bras Nutr Clín. 2003;18:168-72.

6. Dantas RO. Disfagia de pequenas e múltiplas causas. In: Costa M, Castro LP, editores. Tópicos em deglutição e disfagia. Rio de Janeiro: Medsi; 2003. p.83-6.

7. Davis LA, Stanton ST. Characteristics of dysphagia in elderly patients requiring mechanical ventilation. Dysphagia. 2004;19:7-14.

8. de Larminat V, Montravers P, Dureuil B, Desmonts JM. Alteration in swallowing reflex after extubation in intensive care unit patients. Crit Care Med. 1995;23:48690.

9. Donzelli J, Brady S, Wesling M, Craney M. Simultaneous modified Evans blue dye procedure and video nasal endoscopic evaluation of the swallow. Laryngoscope. 2001;111:1746-50.

10. Elpern EH, Scott MG, Petro L, Ries MH. Pulmonary aspiration in mechanically ventilated patients with tracheostomies. Chest. 1994;105:563-6.

11. Faria AMC, Guanaes A. Introdução à ventilação mecanica. In: Barreto SSM, Vieira SRR, Pinheiro CTS, editores. Rotinas em terapia intensiva. $3^{\mathrm{a}}$ ed. Art Med; 2003. p.139-56.

12. Forte AP, Forte V. O impacto da traqueostomia na deglutição. In: Ferreira LP, Befi-Lopes DM, Limongi SCO, editores. Tratado de fonoaudiologia. São Paulo: Roca; 2004. p.405-14.
13. Gomes GF. Manejo clínico das traqueostomias. In: Filho EM, Pisiani JC, Carneiro J, Gomes G, editores. Disfagia - abordagem multidisciplinar. $3^{\mathrm{a}}$ ed. São Paulo: Frôntis; 2000. p.177-86.

14. Leder SB. Incidence and type of aspiration in acute care patients requiring mechanical ventilation via a new tracheotomy. Chest. 2002;122:1721-6.

15. Lopes AC, Borges VC, Andrade Jr A. Desmame da ventilação mecanica. Rev Bras Clín Ter. 1999;25:171-8.

16. MacIntyre NR, McConnell R, Cheng KC, Sane A. Patient-ventilator flow dyssynchrony: flow-limited versus pressure-limited breaths. Crit Care Med. 1997;25:1671-7.

17. O’Neil-Pirozzi TM, Lisiecki DJ, Jack Momose K, Connors JJ, Milliner MP. Simultaneous modified barium swallow and blue dye test: a determination of the accuracy of blue dye test aspiration findings. Dysphagia. 2003;18:32-8.

18. Rumbak MJ, Newton M, Truncale T, Schwartz SW, Adams JW, Hazard PB. Prospective, randomized, study comparing early percutaneous dilational tracheotomy to prolonged translaryngeal intubation (delayed tracheotomy) in critically ill medical patients. Crit Care Med. 2004;32:1689-94.

19. Shaker R, Lang IM. Aging and deglutitive motor function, effect of aging on the deglutitive oral, pharingeal, and esophageal motor function. Dysphagia. 1994;9:221-8.

20. Shapiro BA, Warren J, Egol AB, Greenbaum DM, Jacobi J, Nasraway SA, Schein RM, Spevetz A, Stone JR. Practice parameters for intravenous analgesia and sedation for adult patients in the intensive care unit: an executive summary. Crit Care Med. 1995;23:1596-600.

21. Solh A, Okada M, Bhat A, Pietrantoni C. Swallowing disorders post orotracheal intubation in the elderly. Intensive Care Med. 2003;29:1451-5.

22. Tolep K, Getch CL, Criner GJ. Swallowing dysfunction in patients receiving prolonged mechanical ventilation. Chest. 1996;109:167-72.

23. Vidigal ML, Gonçalves MI. Pacientes traqueostomizados e dependentes de ventilador. In: Furkim A, Santini C, editores. Disfagias orofaringeas. São Paulo: Pró-Fono; 1999. p.121-3.

Recebido em 3/3/2009. Aprovado em 20/5/2009. 